\title{
ПРИНЦИПЫ И КРИТЕРИИ ПЕНАЛИЗАЦИИ ПРЕСТУПЛЕНИЙ
}

\section{PRINCIPLES AND CRITERIA FOR PENALIZING CRIMES}

V. Markov

Summary. The article reveals the essence of the penalization category. The fundamental differences between penalization and criminalization are presented. The need to develop ideas about the principles that extend their effect on the process and result of penalization is theoretically justified. It is noted that the individual principles of penalization are characterized by multi-level and complex structures. It is established that the principles help to model penalization. Analysis of law enforcement practice shows that the principles do not always work. Comparative analysis shows that among scientists there are similar points of view on the problems of the principles of penalization.

Keywords: principle, prevention, crime, criminology, criterion, penalization, complexity.

\author{
Марков Владимир Петрович \\ Д.ю.н., доцент, ФГБОУВО «Самарский \\ государственный экономический университет» \\ ladimirmarkov@gmail.com
}

Аннотация. В статье раскрывается сущность категории «пенализация». Представлены принципиальные отличия пенализации от криминализации. Теоретически обосновывается необходимость развития представлений о принципах, распространяющих свое действие на процесс и результат пенализации. Отмечается, что в отдельные принципы пенализации характеризуются многоуровневостью и сложностью конструкций. Установлено, что принципы помогают моделировать пенализацию. Анализ правоприменительной практики показывает, что принципы не всегда работают. Сравнительный анализ показывает, что среди ученых встречаются похожие точки зрения на проблематику принципов пенализации.

Ключевые слова: принцип, предупреждение, преступление, криминология, критерий, пенализация, комплексность.

яния в процессе уголовной политики, осуществляемой государством.

В рамках данной публикации целью статьи является уточнение сущности, принципов и критериев пенализации.

Обращение к проблематике принципов пенализации требовало внимательного изучения различных точек зрения исследователей. В процессе написания статьи был проанализирован ряд публикаций $[1 ; 2 ; 3 ; 4 ; 7 ; 9 ; 11]$, монографий [8; 10; 14] и диссертаций [13], где уделяется внимание проблемам пенализации, определению перспектив и возможностей. Были проанализированы положения уголовного законодательства РФ, устанавливающего принципы пенализации и депенализации.

Обобщение авторских позиций позволяет отметить, что принципы пенализации и депенализации деяний имеют принадлежность к более абстрактному уровню научного обеспечения и обоснования норм уголовного права, опора на которые имеет ключевое значение для корректировок системы норм уголовного права [10]. В научной литературе подчеркивается, что пенализация характеризует количественный аспект криминализации [9]. Это означает, что сущность пенализации заключается в определении принципов и критериев использования механизма государственного принуждения за преступные деяния, определении целей уго- 
ловного наказания, его форм и размеров. Тем самым пенализацию следует определять как определение вида и размера наказания для принудительного воздействия на совершивших опасное деяние лиц. Содержание депенализации находит отражение в разделе 3 УК РФ «Наказание». Исключение мер государственного принудительного воздействия из системы наказаний, отказ от вынесения меры наказания, и освобождение лица от уголовной ответсвенности следует рассматривать как депенализацию. Анализ мнений А.И. Коробеева [5] и С.Г. Чаадаева [15] позволяет отметить разницу во взглядах на понимание сущности депенализации, где ошибочно отождествляется депенализация с декриминализацией. По мнению Н.А. Лопашенко, основу депенализации составляет принцип гуманизма [12], тем самым считая депенализацию и декриминализацию разноплановыми понятиями.

Критерий - признак, посредством которого можно что-то измерять. Основным критерием выступает качество. Ученые и представители государственных органов власти подчеркивают, что пенализация и депенализация находятся в сильной зависимости от качества законотворчества. Поэтому крайне важно понимание того, каким образом влияет совершенствование норм, правовых институтов пенализации и депенализации на динамику и структуру преступности. Если этого не делать, принятие решений законодателем может ухудшить криминологическую обстановку, вызвать рецидивы. Такая позиция в отношении пенализации и депенализации позволяет их рассматривать как метод уголовной политики и науки. Либерализация уголовной политики выражается в том, что на современном этапе законодатель игнорирует результаты криминологических исследований и экспертиз до принятия законопроектов. Отсюда возникает противоположный эффект в борьбе с преступностью. Чтобы его предупредить - уместно соблюдать принципы.

В современных исследованиях подчеркивается развитие представлений о пенализации как существующей в форме процесса (законодательная деятельность) и в форме результата (нормы уголовного законодательства, которые определяют наказуемость деяний) [3]. Последний компонент особенно важен для функционирования социума. То есть должна существовать взаимосвязь между правовыми санкциями и практикой их применения. Пенализация решает ряд сложных прикладных задач, определяющих цель наказания, и соответствие правовых санкций тенденциям государственной политики. Пенализация преступности требует оценки их социальной опасности, определения принципов и критериев, на основе которых определяются виды наказаний. Моделирование данного процесса конструируется, как на общих принципах уголовного права, так и на част- ных принципах пенализации [2], которыми должен руководствоваться законодатель и орган судебной власти в своей деятельности. Основу депенализации составляет смягчение уголовно-правовых санкций, а также определение в законодательстве системы видов освобождения от наказания и уголовной ответственности (отмена более строгого наказания либо смягчение наказаний и снижение сроков) [5].

Принципы - это руководящие идеи и начала процесса его формирования, развития и функционирования [11]. Такое определение отражает процессуальные характеристики пенализации деяний. Однако, полагаем, такое определение для принципов пенализации и депенализации будет не полным, так как не учитывает взгляды на пенализацию как результат. В контексте результата принципы следует рассматривать как систему правил и критериев оценки, определяющей допустимость, необходимость и целесообразность определения уголовной ответственности за деяния или отмены уголовно-правового запрета. В работах Г.А. Кригера правовой принцип рассматривается в качестве закрепленных в законе идеологических, политических и нравственных начал, выполняющих регулятивную и охранительную функции для задач государственного принуждения и воздействия на общественные отношения [7, с. 102].

Формулирование принципов пенализации и депенализации предпринималось и в древние времена философами, политологами, правоведами. Итогом этой деятельности стало определение допустимого и должного посредством абстрактных принципов и практических рекомендаций по юридическому трактованию норм.

Ядро пенализации составляет принцип справедливости. Статьи 6 и 60 Уголовного Кодекса РФ содержат указание на то, что восстановление принципа социальной справедливости компенсируется применением принципа и целей наказания. Справедливость - понятие многогранное, из чего могут вытекать другие принципы. В отдельных исследованиях [1] подчеркивается относительная сложность понимания правовой конструкции данного принципа, так как он состоит из двух частей: во-первых, соразмерность тяжести наказания тяжести преступления; во-вторых, древнейший правовой принцип «не дважды за одно и то же» (или от лат. non bis in idem). Нередко при масштабных политических изменениях, при вынесении решения судом заложенные в закон правовые гарантии не соблюдаются или забываются. В других случаях индивидуализация характера наказания, зависит от полномочий судебных органов, учитывающих в своей работе степень общественной опасности, обстоятельства и возрастные и психологические особенности личности. 
Таблица 1. Состав принципов пенализации деяний: анализ точек зрения

\begin{tabular}{|c|c|}
\hline Автор & Состав принципов \\
\hline М.М. Имамов (2004) & $\begin{array}{ll}\text { - } & \text { Целесообразность и определенность системы наказаний и каждого отдельного } \\
\text { в } & \text { Дела наказаний, } \\
\text { - } & \text { Заменость видов наказаний; } \\
\text { · } & \text { Соответствие системы наказаний социально-экономическим и политическим } \\
\text { условиям; } & \text { Соответствие системы наказания уровню общественного сознания и культуры; } \\
\text { - } & \text { Построение системы с учетом традиций; } \\
\text { - } & \text { Обусловленность системы наказания содержанием правового регулирования. }\end{array}$ \\
\hline Лопашенко Н.А. (2009) & $\begin{array}{ll}\text { · } & \text { Принцип справедливости; } \\
\text { · } & \text { Принцип наказания. }\end{array}$ \\
\hline Сабитов Т.Р. (2012) & $\begin{array}{ll}\text {. } & \text { Принцип пенализации и криминализации: } \\
\text { · } & \text { Принцип целесообразности уголовно-правового запрета и принцип } \\
\text { ответсвенности за его нарушение; } \\
\text { · } & \text { Экономия репрессии; } \\
\text { · } & \text { Принцип пенализации: } \\
\text { - Дифференциация ответственности; }\end{array}$ \\
\hline Густова Э.В. (2012) & 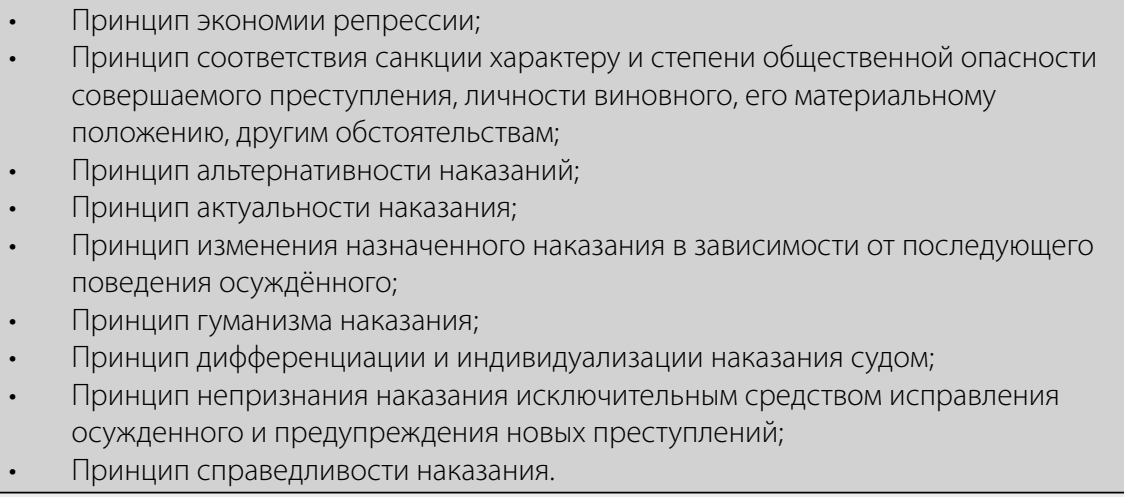 \\
\hline Каземиров А.М. (2016) & $\begin{array}{ll}\text { · } & \text { Принцип дифференциации ответственности; } \\
\text { - } & \text { Принцип соответствия санкции характеру и степени общественной опасности } \\
\text {. } & \text { Принциления; } \\
& \text { Принцооветствия санкции целям наказания. }\end{array}$ \\
\hline Автор публикации (2021) & · Принцип комплексности пенализации деяния \\
\hline
\end{tabular}

Анализ юридической литературы (Э.В. Густова [4], Т.Р. Сабитов [14]) позволяет отметить, что реализации данного принципа во многом способствует использование в процессе пенализации принципа гуманизма наказания, принципа экономии репрессии, принципа актуальности наказания, принципы дифференциации и индивидуализации наказания, принцип концентрации репрессии, принцип способствования наказания исправлению осужденного. Следует отметить, большинство из данных принципов имеет философское, социальное и юридическое значение, хотя специально по этим критериям принципы не дифференцируют в научной литературе [11]. Принципы помогают моделировать процесс и результат пенализации, если правовые нормы, отражают виды наказания, способны предотвратить деяние, и дать адекватную оценку совершенному деянию [2]. Н.В. Бугаевская обращает внимание на тот факт, что, несмотря на определение должного в законе, пра- воприменительная практика идет в разрез с моделями пенализации деяний, определенными законодателем. Поэтому ученый отстаивает мнение о необходимости комплексного подхода для выбора адекватного и справедливого реагирования на совершенное деяние. Соглашаясь с данным мнением, необходимо подчеркнуть, реализация такого подхода на практике, требует учета и введения в юридический оборот и в практику пенализации деяний принципа комплексности, интегрирующего в себе законодательные нормы и правоприменительную практику.

Анализ точек зрения ученых-правоведов дает определенные представления о существующих видах принципов пенализации и их содержании. В отдельных случаях можно говорить о сближении научных позиций в отношении принципов пенализации. Данные сравнительно-правового анализа представлены в Таблице 1. 
Оценка каждого из мнений показывает, что авторы делают попытку определить принадлежность принципов к пенализации, и в отдельных случаях допускают неточности (Э.В. Густова), потому что они никак не воздействуют на законодательный процесс. Полагаем при определении принципов крайне важно представлять суть процедуры пенализации, находящаяся в компетенции и практике работы органов судебной системы, в деятельности которых законодательная наказуемость не совпадает с фактической наказуемостью. Другой автор (Т.Р.Сабитов) относит лишь отдельные принципы к пенализации в чистом ее виде; остальные - еще и к криминализации.

Таким образом, можно отметить некоторое сближение авторских позиций в отношении проблематики принципов пенализации (М.М. Имамов, Э.В.Густова, а также Т.Р. Сабитов и М.М. Каземиров). Учитывая многогранность и многоуровневость каждого принципа, принципы пенализации следует определять как систему правил и критериев оценки для определения степени ответственности за деяние. Однако, следует подчеркнуть, что данные принципы должны распространятся на процесс и результат пенализации. То есть пенализация носит комплексный характер - это на практике должно означать, что правовые нормы, должны отражать виды наказания, быть способны предотвратить деяние, и позволят адекватную оценку совершенному деянию, а применяющие их судебные органы должны выработать и принять адекватное и справедливое решение. Поэтому считаем, принцип комплексности в пенализации требует своего обоснования и внедрения. Следует полагать, такой подход позволяет понять, на каком этапе процесса пенализации (законодательный, судебный) данный принцип не работает, какие принципы иерархии нарушаются, и какой будет от этого результат. То есть предлагаемый принцип будет составлять основу правового мониторинга.

\section{ЛИТЕРАТУРА}

1. Бунин 0.Ю. Справедливость уголовного закона / 0.Ю. Бунин // Ученые записки Крымского федерального университета имени В.И. Вернадского.2013.— № 2.— Вып.26. - С. 257-265.

2. Бугаевская Н.В. Создание эффективной модели пенализации и конструирования санкций за коррупционные преступления / Н.В. Бугаевская // Уголовно-исполнительное прав0.— 2020.— - Т. 15.— № 3.— С. 317-323.

3. Валеев М.Т. Формы пенализации общественно опасных деяний / М.Т. Валеев // Вестник Кузбасского института. — 2020.— № 3.— С. 13-18.

4. Густова Э.В. Криминализация и пенализация деяний как формы реализации уголовной политики / Э.В. Густова // Вестник Воронежского института МВД России.-2014. - № 1.- - С. 224-228.

5. Коробеев А.И. Советская уголовно-правовая политика: проблемы криминализации и пенализации / А.И. Коробеев.- Владивосток: Изд-во Дальневосточного ун-та, 1987. - 267с.

6. Коробеев А.И. Полный курс уголовного права: в 5 томах / [ред. А.И. Коробеев] / Учебное пособие.— Т. 1.— СПб.: Юрид. центр Пресс, 2008. — 1133 с.

7. Кригер Г.А. Место принципов уголовного права в системе принципов права / Г.А. Кригер // Советское государство и право.— М.: Наука, 1981.— № 2.— С. 102-107.

8. Криминализация и декриминализация как формы преобразования уголовного законодательства / В.П. Кашепов, Н.А. Голованова, [и др.]; [ред. В.П. Кашепов] / Монография. - М.: Институт законодательства и сравнительного правоведения при Правительстве РФ, 2018. ख $280 \mathrm{C.}$

9. Мизяков А.А. Криминализация и декриминализация в уголовном праве / А.А. Мизяков // Бизнес в законе.— 2009.—№ 5.—C. $165-167$.

10. Основания уголовно-правового запрета: криминализация и декриминализация /П.С. Дагель, Г.А. Злобин, С.Г. Келина [и др.]; [ред. В.Н. Кудрявцева, А.М. Яковлева] / Монография.- М.: Наука, 1982.— 712 с.

11. Прысь Е.В., Митюкова Ю.А. Принципы криминализации и декриминализации деяний в экономической сфере (криминологический и гражданско-правовой аспекты) / Е.В. Прысь, Ю.А. Митюкова // Юридическая наука и правоохранительная практика. — 2015.— № 2.— C. 75-79.

12. Российское уголовное право: [общая и особенная части]: [в 3 т.] Том 1 / [ред. Н.А. Лопашенко], [С.В. Анощенкова и др.] / Учебное поосбие.—- 2-е изд., испр. и доп.—-.: Юрлитинформ, 2014.- 719 с.

13. Сабитов Т.Р. Уголовно-правовые принципы: понятие, система и виды / Т.Р. Сабитов / Автореферат дис. ... доктора юридических наук: 12.00.08. — Екатеринбург, 2019. - 54 с.

14. Сабитов Т.Р. Система уголовно-правовых принципов / Т.Р. Сабитов [ред. А.И. Чучаев] / Монография.— М.: Проспект, 2012.— 240с.

15. Чаадаев С.Г. Уголовная политика и преступность: проблемы и пути решения / С.Г. Чаадаев / Учебное пособие.— М.: 3нание, 1991.— $112 c$.

() Марков Владимир Петрович ( ladimirmarkov@gmail.com ).

Журнал «Современная наука: актуальные проблемы теории и практики» 